\title{
Os Processos de Identificação na Adolescência e sua Relação com Obras Literárias: Relato de Pesquisa
}

\author{
Marina Gonçalves Gonzaga dos Santos ${ }^{1}$ \\ ${ }^{1}$ Universidade Federal de São Paulo, SP, Brasil.
}

\author{
Sidnei José Casetto ${ }^{1}$ \\ ${ }^{1}$ Universidade Federal de São Paulo, SP, Brasil.
}

Resumo: A adolescência corresponde a um fenômeno cultural e moderno, que implicou uma mudança na sensibilidade relativa à puberdade e à infância. A ela associou-se o surgimento de uma moratória social como imposição da espera de aproximadamente dez anos para os púberes atingirem a condição de adultos. Quanto ao aspecto psíquico, a adolescência se caracteriza pelo retorno de questões de caráter edípico, o que a torna um período de conflitos e afetos a serem elaborados. Freud destaca a importância da identificação na formação do Eu e da personalidade. As obras literárias podem constituir-se em meio de comunicação com aspectos inconscientes, auxiliando na representação de seus conteúdos. Este trabalho tem como objetivo analisar os processos de identificação com personagens literários na adolescência. Foram realizadas entrevistas com estudantes do Ensino Médio: a primeira entrevista, semiestruturada, contou com a participação de 26 adolescentes; para a segunda entrevista, não estruturada, foram selecionados quatro estudantes dentre esses 26 . Com a análise das entrevistas foram encontrados três principais tipos de aspectos de identificação com personagens literários: identificação com quem já se é; identificação com quem se gostaria de ser; e identificação com quem se gostaria de ter como par. Foi possível perceber também aspectos identificatórios de reparação narcísica, pela eleição de personagens que vencem os obstáculos que lhes são impostos. Tais narrativas parecem auxiliar a equacionar a moratória social imposta aos adolescentes. Também se percebeu que a literatura pode servir como um recurso transicional, de forma a oferecer acesso a possibilidades de vida social, amorosa e profissional.

Palavras-chave: Adolescência, Literatura, Identificação.

\section{Identification Processes in Adolescence and their Relation to Literary Works: A Research Report}

\begin{abstract}
Adolescence corresponds to a cultural and modern phenomenon that implies a change in the perception of the distinctness between puberty and childhood. This was associated with the emergence of a social moratorium as an imposition of an approximately ten-year wait until the youngsters could be considered as adults. The psychic aspect of adolescence is marked by the return of Oedipal matters, which reinforces adolescence as a period of revived conflicts and affects that must be elaborated. Freud highlights the importance of identification when considering its participation crucial to the constitution of Ego and personality. Literary works can work as a means of communication for unconscious aspects, as they can help in the representation of its matters. The objective of this study was to analyze the processes of identification with literary characters in adolescence. Interviews were carried out with students attending high school: the first interview was semi-structured and counted with the participation of 26 adolescents; for the second, non-structured interview, 4 students were selected among these 26. Analyzing the interviews, we found three main types of identificatory aspects with literary characters, which are: identification with who you already are; identification with who
\end{abstract}


you would like to be; and identification with who you would like to have as a partner. When examining the narratives of the most mentioned literary characters we noticed what seems to be identificatory aspects of narcisical reparation considering the preference for characters who invariably overcome the obstacles that are set. Those narratives also seem to equate the social moratorium that is imposed to the adolescents. We also realized that literature may work as a transitional resource, offering access to possibilities of social, love and professional lives.

Keywords: Adolescence, Literature, Identification.

\title{
Los Procesos de Identificación en la Adolescencia y su Relación con Obras Literarias: Relato de Investigación
}

\begin{abstract}
Resumen: La adolescencia corresponde a un fenómeno cultural y moderno, que implica un cambio en la sensibilidad relativa a la pubertad y la infancia. A ella se asoció el surgimiento de una moratoria social como imposición de una espera de aproximadamente diez años para que los púberes pudieran alcanzar la condición de adultos. En lo que se refiere al aspecto psíquico, la adolescencia se caracteriza por el retorno de cuestiones de carácter edípico, lo que la convierte en un período de conflictos y afectos a ser elaborados. Freud destaca la importancia de la identificación en la formación delYo y de la personalidad. Las obras literarias pueden constituirse como un medio de comunicación con aspectos inconscientes al auxiliar en la representación de sus contenidos. Este trabajo tuvo como objetivo analizar los procesos de identificación con personajes literarios en la adolescencia. Se realizaron entrevistas con estudiantes de la enseñanza media: la primera entrevista, semiestructurada, contó con la participación de 26 adolescentes; para la segunda entrevista, no estructurada, se seleccionaron a 4 estudiantes entre los 26 . Del análisis de las entrevistas encontramos tres principales tipos de aspectos identificatorios con personajes literarios: identificación con quien ya es; identificación con quien quisiera ser; e identificación con quien quisiera tener como pareja. Pudimos percibir también aspectos identificatorios de reparación narcísica, por la elección de personajes que vencen los obstáculos que les son impuestos. Estas narrativas también parecen auxiliar a ecuacionar la moratoria social impuesta a los adolescentes. También percibimos que la literatura puede servir como un recurso transicional por ofrecer acceso a posibilidades de vida social, amorosa y profesional.
\end{abstract}

Palabras clave: Adolescencia, Literatura, Identificación.

\section{Introdução}

\section{A adolescência}

Com as contribuições de Ariès (1981), foi possível desnaturalizar a infância, recuperando o processo histórico de sua constituição. A adolescência, tal qual a conhecemos hoje, seria, assim como a infância, uma invenção proveniente da modernidade (Calligaris, 2000). Isto de maneira alguma significa que anteriormente não houvesse uma distinção entre as faixas etárias. Apenas, como explicitado por Calligaris (2000), até a modernidade, a adolescência e a infância não existiam como símbolos culturais, ou seja, como grupos idealizados e catalogados pela cultura. A modernidade contribuiu para tal mudança, adotando o individualismo como um de seus principais valores e modificando concepções sustentadas pela sociedade tradicional.

Tomando Ariès (1981) como base, Calligaris (2000) argumenta que a infância, como uma entidade social, vingou devido ao modo como o individualismo encarava a morte. Em um momento anterior, a morte não tinha o mesmo caráter fatalista que lhe é atribuído atualmente. A experiência de comunidade era mais fortalecida e, justamente por isto, ultrapassava a morte, uma vez que o eventual 
falecimento de alguns de seus membros não ameaçava sua continuidade, na medida em que os demais a perpetuariam. No entanto, com o individualismo, a comunidade se enfraquece: "indivíduo" advém de indivisível, único. E, em uma sociedade com essa característica, as experiências são encorajadas a serem percebidas e traduzidas pelo sujeito, de forma a buscar em si próprio, em seu "interior", o sentido de suas vivências. Ora, seguindo tal raciocínio, o sentido da morte, sendo este restrito ao próprio indivíduo, seria, portanto, o fim de tudo, uma vez perdida a comunidade como propagadora de seu legado. A infância teria surgido justamente para preencher tal lacuna deixada pelo enfraquecimento da comunidade: as crianças assumiriam o papel de representação da continuidade para além da morte.

É perceptível como a infância tornou-se um período idealizado, para o qual todos olham com encantamento, associado a inocência, pureza etc. Com isso, a infância se consolidou como uma entidade social. No entanto, com o estabelecimento da infância como uma fase da vida, destacou-se um período que não poderia se encaixar dentro dela. Uma etapa que se assemelhava à da vida adulta, em que não mais se agia como agem as crianças, embora os adultos não a enxergassem como suficientemente madura para encará-la de igual para igual. Com isso, juntamente com o nascimento da infância, surge a adolescência: uma espécie de limbo que categoriza aqueles que não são mais crianças, porém ainda não adultos.

O limbo que a adolescência representa é descrito por Calligaris (2000) como uma moratória. Quando atingem a puberdade, os jovens adquirem o que os diferenciava dos adultos: o corpo maduro. Era de se esperar que, uma vez que estivessem fisiologicamente "prontos", tendo recebido a herança cultural na infância, pudessem encarar as responsabilidades adultas e serem plenamente inseridos na organização social. No entanto, é lhes imposto que ainda aguardem cerca de dez anos para que possam ser considerados adultos.

Segundo Calligaris (2000), a puberdade estabelece a marca que nos permite identificar o início da adolescência. Para Freud (2016), a puberdade seria marcante, pois viria a definir a configuração da vida sexual do indivíduo. Ainda na infância, a vida sexual havia atravessado um período de autoerotismo. Com o complexo de Édipo, fora definido um objeto sexual, mas vedado pela cultura e inviável por sua imaturidade física. Na puberdade, com o desenvolvimento do aparelho reprodutor, o indivíduo é convocado a encontrar outro objeto sexual.

Ainda segundo Freud (2016), o caminho mais curto para o indivíduo na puberdade, quando convocado a eleger um objeto sexual, seria escolher alguém em quem já investia sua libido desde a infância: seus pais ou pessoas que assumam esta posição. No entanto, durante o período de latência, enquanto aguarda sua maturação sexual, o sujeito pode absorver os ideais da sociedade que the foram passados pelas mais diversas instâncias, como a escola, a família, a cultura etc. Logo, uma vez na puberdade, o sujeito já será capaz de compreender as exigências da sociedade, sendo uma das mais significativas a barreira do incesto. Consequentemente, os sujeitos nos quais o jovem vinha investindo sua libido estão interditados: é proibido que o jovem eleja seus familiares como objetos sexuais, e ele costuma submeter-se a tal restrição.

Tal tarefa é árdua para os jovens. Pinheiro (2001) define o período da adolescência como o momento em que as questões edípicas retornam, e quando o fazem, estão ainda mais fortes. Isso acontece pois, como elucidado por Freud (2016), durante o período de latência, o investimento libidinal incestuoso empregado pela criança é desviado para o saber. Por se tratar apenas de um desvio, é natural que, ao final de tal período, as questões que este postergou retornem. A adolescência seria um período especialmente crítico, pois, além do retorno das questões edípicas, haveria também a percepção do jovem de não ocupar mais o lugar que ocupava para os pais durante a infância, no qual recebia deles afeto e cuidados intensivos.

Frente a tal cenário, o adolescente se vê obrigado a não somente abandonar um objeto muito investido, por ser incestuoso, mas também abandonar a configuração de garantias que este objeto lhe proporcionava. É necessário que o adolescente busque um objeto sexual fora de seu círculo familiar, mas, como esclarecido por Freud (2010), os novos objetos não passarão de substitutos do objeto no qual o jovem originalmente investiu sua pulsão. É uma situação desafiadora para o jovem, o que pode justificar a ambivalência de sentimentos e afetos do adolescente em relação ao mundo que o circunda durante tal período de sua vida, como também suas alterações de humor e a frequente atitude de revolta.

Considerando que o jovem tem suas expectativas de se integrar à vida adulta frustradas pela moratória social, é plausível que a raiva que o adolescente dirija 
ao mundo externo seja também uma reação. Logo, atacar o mundo externo que o exclui seria uma resposta a como este se sente interditado por tais imposições.

Pinheiro (2001) também ressalta como a adolescência é o período no qual a castração é convocada a ser elaborada e, principalmente, aceita pelo jovem. No entanto, frente ao turbilhão de emoções que este enfrenta, é comum que o púbere se utilize de seu recuo narcísico como um recurso para negar o confronto com a castração, e é a partir de tal proteção narcísica que surgiria a atitude onipotente, tão observável em muitos jovens, como o meio encontrado para resistir aos limites impostos.

Segundo André (2001, p. 30), "quando o conflito intrapsíquico se revela impossível de se negociar, quando o mundo interno excede as capacidades de simbolização, denunciar o exterior passa a ser o único recurso". Retomando a questão da posição onipotente do adolescente, também é relevante ressaltar que "é preciso que o adolescente encontre onde escoar a onipotência e o seu avesso de tristeza, luto e solidão" (Pinheiro, 2001, p. 75).

No contexto brasileiro atual, a adolescência também coincide com o período no qual, geralmente, ocorre a escolha profissional, uma vez que os jovens são convocados a prestar o vestibular, a fim de ingressar na universidade. Assim, considerando a pressão que circunda tal período de preparação para a vida profissional, é possível que este também se constitua num período no qual "o adolescente busca saídas que lhe permitam conquistar como adulto um lugar próprio" (Soares, Aguiar, \& Guimarães, 2010, p. 135).

Os jovens que atravessam o período da adolescência enfrentam diversos conflitos no âmbito psíquico, como anteriormente ressaltado, e é interessante questionar quais recursos têm sido utilizados para que estes consigam lidar com tal turbulência e que meios poderiam auxiliar na simbolização das questões que tanto os perturbam.

Observando os adolescentes atualmente, é possível destacar alguns objetos da cultura que são populares entre eles, que parecem ajudá-los a lidar com a complexidade do período que enfrentam, como os videogames, os seriados, os filmes e, também, a literatura. Supomos que tais produções possam ecoar suas próprias experiências, a eles permitindo alguma identificação com os personagens e situações retratados. Neste trabalho iremos investigar os processos identificatórios envolvidos na relação com estes recursos, particularmente a literatura.

\section{A identificação}

Segundo Freud (2011b, p. 46), “a psicanálise conhece a identificação como a mais antiga manifestação de uma ligação afetiva a uma outra pessoa". Em sua obra "O Eu e o Id", Freud (2011a) destaca a importância da identificação por supostamente substituir um investimento objetal de um objeto que foi perdido, restabelecendo-o no Eu. Essa elucidação se deu por meio da observação do fenômeno da melancolia, no qual, após o sujeito sofrer uma decepção de seu objeto de investimento, a libido nele investida recua para o Eu, estabelecendo uma identificação. Logo, o Eu acaba por se identificar com o objeto abandonado, e o automartírio presente na melancolia seria uma hostilidade dirigida ao objeto original (Freud, 2010).

Por outro lado, esse processo de identificação não ocorreria somente na melancolia, sendo que "tal substituição participa enormemente na configuração do Eu e contribui de modo essencial para formar o que se denomina seu caráter" (Freud, 2011a, p. 35, grifo do autor). Grunberger e Chasseguet-Smirgel (1997) supõem que tal percepção acerca das identificações, e como estas influenciariam a formação da personalidade do sujeito, está entre os motivos que levaram Freud a revisar sua teoria estrutural do aparelho psíquico, propiciando a elaboração da chamada segunda tópica, constituída pelo Eu, o Super-eu e o Id.

Segundo Freud (2011b), na pré-história do complexo de Édipo, o garoto expressa desejo de ser como o pai, tomando-o como seu ideal. Logo, pode-se dizer que há uma identificação do garoto com seu pai neste momento, uma vez que este o toma por modelo. No entanto, ao mesmo tempo em que mantém identificação com o pai, o garoto também investe em sua mãe como objeto. O complexo de Édipo típico se daria quando o garoto percebesse o pai como obstáculo em sua relação com a mãe e a identificação que mantinha com este assumiria um caráter hostil. O garoto, que antes elegia o pai como modelo a ser seguido, agora deseja tomar seu lugar junto à mãe (Freud, 2011b). Isso aconteceria pois, de acordo com Freud (2011b, p. 47), "desde o início, a identificação é ambivalente, pode tornar-se tanto expressão de ternura como desejo de eliminação".

Ao fim do complexo de Édipo, é necessário que o investimento objetal na mãe seja abandonado, 
dando lugar a uma identificação com ela ou a um fortalecimento da identificação com o pai. Na menina, analogamente, o complexo de Édipo pode resultar num fortalecimento da identificação com a mãe ou no estabelecimento de uma identificação com o pai (Freud, 2011a).

Freud (2011a) ressalta como, principalmente em neuróticos, o complexo de Édipo se dá majoritariamente de maneira completa, ou seja, há uma versão positiva e uma versão negativa. Isso significa que o menino, por exemplo, não somente se identificaria com o pai e teria uma relação objetal terna com a mãe, mas também se identificaria com esta, mostrando, por vezes, uma atitude feminina em relação ao pai.

O resultado do complexo de Édipo seria um precipitado no Eu, que se constitui por meio dessas duas identificações. Este precipitado seria o que Freud (2011a) categorizou como o Super-eu, que conservaria as características dos pais, tanto na advertência acerca do que o sujeito deve ser quanto na proibição do que o sujeito não deve ser. Ao longo de seu desenvolvimento, figuras de autoridade levariam adiante $o$ papel do pai no Super-eu, uma vez que também atuariam proibindo e advertindo o sujeito. Logo, pode-se dizer que "os sentimentos sociais repousam em identificações com outras pessoas, com base no mesmo ideal do Eu1" (Freud, 1923a, p. 34).

\section{As obras literárias}

A experiência da leitura de obras literárias é um tema que, no âmbito da Psicanálise, teve o trabalho de Bruno Bettelheim (1903-1990) como um dos mais bem desenvolvidos sobre o assunto, servindo como referência para a maioria dos estudos posteriores. Bettelheim foi um psicanalista austríaco que se interessou principalmente pela relação que as crianças mantinham com os contos de fadas, analisando não somente os aspectos de tal relação como também os contos em si pela ótica da psicanálise em sua obra A psicanálise dos contos de fadas (1976).

Segundo Bettelheim (2015), as histórias são de extrema importância para o desenvolvimento, contribuindo para ele de diversas maneiras. Isso aconteceria pois, durante o período de desenvolvimento, as crianças se confrontariam com decepções narcísicas, dilemas edípicos, rivalidades fraternas, entre outros problemas de caráter psicológico. A maioria das histórias, que, de algum modo trazem um protagonista que, ao transpor fronteiras e vencer obstáculos, emerge vitorioso, acabaria por conversar com o ego em desenvolvimento, encorajando que este se fortaleça.

Bettelheim (2015) ainda ressalta como as histórias também são capazes de atuar sob as pressões pré-conscientes e inconscientes, aliviando-as. Isso aconteceria pois, devido à estimulação da imaginação que as histórias proporcionam, o material inconsciente teria certa permissão para vir à tona sem, no entanto, causar muitos danos ao sujeito. Muitas vezes, as histórias também são tomadas pela fantasia na qual não há sempre uma lógica formal, uma temporalidade linear etc., o que também se mostra compatível com o inconsciente.

À semelhança do anteriormente referido por André (2001), Bettelheim (2015) afirma que, caso as pressões interiores assumam o controle do indivíduo, o único modo que este pode retomá-lo seria exteriorizando-as. Assim, as histórias representariam um papel importante por oferecer personagens nos quais, por meio de identificações, seria possível representar as questões do mundo interno do sujeito que estão excedendo suas capacidades de simbolização.

Satrapa (2002) também explora o uso de histórias como um recurso terapêutico, porém buscou aplicá-las em adultos, mais especificamente pacientes hospitalizados. Por se tratar de adultos, Satrapa ressaltou que outros formatos de histórias, que não somente os contos de fada, poderiam exercer uma função terapêutica nos sujeitos. Seu trabalho também indica como há aspectos dissociados no sujeito, com os quais este consegue entrar em contato mais facilmente com o auxílio das histórias. De acordo com esta autora, para que exerça uma função terapêutica, seria necessário que "uma história [...] apresente o conflito, a angústia dele decorrente, a solução encontrada pelo sujeito e as consequências dessa solução" (Satrapa, 2002, p. 59).

Em suma, as histórias se utilizam de uma linguagem simbólica que possibilita representar conteúdos inconscientes e se relacionar com eles. Ao oferecer um personagem que auxilie na integração da realidade psíquica, as histórias acabariam por facilitar o processo que o sujeito encara ao tentar encontrar um

\footnotetext{
${ }^{1}$ Neste texto, Freud utiliza o termo "Ideal do Eu” como correspondente ao Super-eu, que seria formulado como conceito em sua obra logo depois.
} 
sentido para as experiências que vivencia. Segundo Satrapa (2002, p. 59), é por meio de tal processo que se torna possível "desencadear um movimento associativo e (re)estabelecer a comunicação entre o paciente e seu mundo interno", o que o caracterizaria como terapêutico.

Há uma característica marcante na utilização de histórias como recurso terapêutico que se deve a seu caráter de transicionalidade ${ }^{2}$, como descrito por Satrapa (2002). Deste modo, o sentido das histórias não é algo imposto ao sujeito que entra em contato com elas, tendo liberdade para interpretá-las e associá-las de acordo com suas necessidades e seus interesses. Isso permite que o sujeito estabeleça uma comunicação entre tensões advindas do contato tanto com a realidade externa quanto com a interna, $\mathrm{e}$ encontra nas histórias uma ferramenta para aliviá-las, contribuindo também para o desenvolvimento de sua capacidade simbólica.

Como no presente trabalho buscou-se tratar da adolescência, pode-se considerar que nela, assim como na infância ou na fase adulta, há aspectos inconscientes, fontes de angústia, a serem simbolizados, e que se poderia fazer uso das histórias como forma de auxílio. Como mencionado, a adolescência é um período crítico, uma vez que convoca o enfrentamento de questões anteriormente postergadas, ao mesmo tempo que se vive uma moratória social que produz frustração. Em um momento como tal, é necessário que o jovem que enfrenta tal período seja capaz de arranjar meios para manejar suas angústias, principalmente as relativas a conflitos inconscientes.

Candido (2004) ressalta a importância da literatura ao considerar que ela, ao dialogar com o inconsciente, teria grande impacto como instrumento de instrução e educação, justamente por seu potencial formador da personalidade. À sua semelhança, Saraiva, Kaspari e Welter (2018) destacam como o encontro com obras literárias pode oferecer possibilidades, ao leitor, pela representação de cenários análogos a seu contexto histórico e social. Discutindo uma proposta de leitura de textos literários no ensino básico, Saraiva, Mügge e Kaspari (2019) apontam para efeitos, inclusive afetivos e corporais, da experiência estética literária, envolvendo a identificação com o outro e o posicionamento de si.
A literatura é capaz de apresentar ao leitor, em uma linguagem simbólica, histórias marcadas por imprevistos e enfrentamentos, nas quais há sempre uma dificuldade a ser superada e cujo personagem principal, na maioria das vezes, é capaz de contornar tais obstáculos e vencê-los. Como apontado por Corso e Corso (2006), por meio das fantasias presentes nas histórias, podemos refletir acerca de nossa própria existência e como a estamos conduzindo. Deste modo, as histórias podem atuar ilustrando nossos temores, desejos, auxiliando na percepção de questões ainda obscuras. De modo geral, "o certo é que escolhemos aqueles enredos que nos falam de perto, mas não necessariamente de forma direta, pode[ndo] ser uma identificação tangencial, enviesada" (Corso \& Corso, 2006, p. 21).

\section{Método}

O presente trabalho utiliza-se da abordagem qualitativa de pesquisa, descrita por Minayo (1994, p. 21) como a metodologia que se ocupa do que não se pode quantificar, trabalhando com "o universo de significados, motivos, aspirações, valores e atitudes, o que corresponde a um espaço mais profundo das relações, dos processos e dos fenômenos que não podem ser reduzidos à operacionalização de variáveis". Silva e Menezes (2005) ressaltam ainda como a abordagem qualitativa leva em consideração uma relação dinâmica entre um sujeito e o mundo real no qual ele está inserido, observando o vínculo entre a objetividade do mundo e a subjetividade do sujeito.

O referencial teórico utilizado nesta pesquisa é a Psicanálise, caracterizando-a como uma pesquisa na qual, segundo Figueiredo e Minerbo (2006, p. 259), "alguns conceitos psicanalíticos são mobilizados como instrumentos para a investigação e compreensão de variados fenômenos sociais e subjetivos".

Por se tratar de pesquisa com seres humanos, o projeto foi submetido para avaliação do Comitê de Ética da Universidade Federal de São Paulo e aprovado sob o $\mathrm{n}^{\circ} 2.106 .398$. Considerando que os entrevistados eram menores de idade, seus respectivos responsáveis assinaram o termo de consentimento livre e esclarecido (TCLE), enquanto os participantes que se dispuseram assinaram um termo de assentimento.

\footnotetext{
${ }^{2}$ Segundo Winnicott (1971/1975, p. 15), a transicionalidade faz referência à “área intermediária entre o subjetivo e aquilo que é objetivamente percebido".
} 


\section{Participantes}

A proposta inicial da pesquisa visava trabalhar com cinco participantes, sendo todos estudantes de uma instituição privada de ensino situada em Santos (SP), que aceitou que a divulgação da pesquisa pudesse ser feita com seus estudantes de ensino médio, a fim de recrutar voluntários. O método escolhido para o recrutamento dos voluntários consistiu em brevemente apresentar a pesquisa em sala de aula e deixar uma folha em cada classe para que os interessados assinassem e informassem um número de telefone para contato. No total, 55 alunos assinaram as folhas de recrutamento, demonstrando interesse. Decidimos que todos os interessados deveriam ser abarcados numa primeira etapa da pesquisa, sendo que, dentre estes, cinco seriam selecionados para participar da segunda etapa. Contudo, dos 55 alunos que demonstraram interesse, apenas 26 participaram da pesquisa de fato, sendo que o restante ou não respondeu quando contatado, ou simplesmente não apareceu no horário marcado para a participação no estudo. No caso dos alunos que responderam ao contato, mas faltaram, foi tentado remarcar pelo menos mais uma vez, mas, caso faltassem novamente, entendeu-se que não desejavam mais participar da pesquisa.

Dos 26 participantes da pesquisa, cinco foram selecionados para a segunda etapa do estudo. No entanto, apenas quatro compareceram, sendo que a quinta estudante remarcou o horário previamente agendado duas vezes e, após faltar em ambas, deixou de estabelecer contato.

O estudo foi realizado ao longo do segundo semestre de 2017, e, entre os 26 estudantes entrevistados, 22 pertenciam ao gênero feminino e 4 ao masculino, sendo que 12 cursavam o primeiro ano do Ensino Médio, 6 o segundo, e 8 o terceiro no momento da entrevista.

Os critérios para a seleção dos cinco entrevistados que participaram da segunda etapa do estudo foram baseados na relação que mantinham com os personagens de obras literárias, priorizando aqueles que tivessem estabelecido identificações mais explícitas com personagens literários. Também consideramos: o entrevistado haver indicado um ou mais personagens provenientes de obras literárias quando questionado sobre ter um personagem que considerasse como seu favorito; o entrevistado ter explicitado aspectos identificatórios com o personagem indicado como favorito; e o entrevistado haver mencionado outros personagens e outras obras literários ao longo da entrevista, assim como ter demonstrado maior abrangência de interesse quanto aos gêneros literários, indicando maior ligação com a literatura, no geral.

\section{Procedimentos}

Nesta pesquisa, foram desenvolvidas duas entrevistas com os estudantes selecionados, sendo a primeira uma entrevista semiestruturada, realizada com todos os estudantes que manifestaram interesse e compareceram na data acordada, e a segunda, uma entrevista não estruturada, realizada com quatro dos 26 entrevistados.

Manzini (1990/1991) classifica a entrevista semiestruturada como aquela na qual o pesquisador desenvolve um roteiro com perguntas principais que serão complementadas por outras questões que podem emergir durante o momento da entrevista. Para Triviños (apud Manzini, 1990/1991), seriam os questionamentos propostos no roteiro básico da entrevista semiestruturada que levantariam novas hipóteses a partir das respostas dos participantes do estudo. A entrevista semiestruturada seria a "mais adequada quando desejamos que as informações coletadas sejam fruto de associações que o entrevistado faz, emergindo, assim, de forma mais livre" (Manzini, 1990/1991, p. 154).

As entrevistas semiestruturadas foram utilizadas em um primeiro contato com os participantes com o objetivo de obter um panorama da relação que estes mantinham com obras literárias no geral ou com alguma obra em específico. Estas foram realizadas na instituição privada de ensino com a qual estabelecemos parceria, em uma sala de reuniões reservada para a realização das entrevistas. A sala contava com uma mesa e cerca de seis cadeiras dispostas junto a esta, iluminação e ventilação artificiais. A duração das entrevistas foi de aproximadamente 30 minutos. O horário em que estas se realizaram foi acordado com os participantes, ocorrendo, geralmente, durante o intervalo de almoço ou após as aulas, no período da tarde.

Após a primeira entrevista, as obras que continham os personagens citados pelo participante selecionados para a segunda etapa foram lidas pela pesquisadora, de modo que, na segunda entrevista, tais personagens puderam ser mais bem discutidos. Em um segundo encontro, a entrevista com os participantes foi não estruturada, classificada por Queiroz (apud Manzini, 2004) como uma entrevista livre, na qual o entrevistador busca limitar ao máximo suas intervenções, visando 
que o entrevistado conduza a entrevista na direção que preferir. As entrevistas não estruturadas se iniciam com uma pergunta "que serve como estímulo e as informações emergem das associações e experiências do entrevistado" (Manzini, 2004, p. 154). Este formato de entrevista foi escolhido para um segundo encontro com os participantes pois, após um contato com as obras citadas durante a primeira entrevista, o objetivo foi de nos aprofundar nos processos de identificação que o entrevistado pareceu manter com um personagem ou personagens das obras literárias previamente citadas.

$\mathrm{O}$ registro de ambas as entrevistas foi realizado após seu fim por meio da transcrição do que foi dito. Não foi realizado nenhum tipo de gravação eletrônica das entrevistas, seja de áudio ou imagem, para evitar o constrangimento do entrevistado.

A análise das entrevistas buscou compreender os processos de identificação com personagens de obras literárias e sua relação com a adolescência, e se baseou na teoria psicanalítica. A interpretação das entrevistas foi baseada em recursos técnicos da Psicanálise, tais como citados por Figueiredo e Minerbo (2006, p. 263):

uma escuta flutuante, isto é, descentrada do tema central, intencionado; um recorte do texto privilegiando temas, expressões, brechas, palavras, ou quaisquer elementos que sirvam como cunha para desconstruir o texto; uma reconstrução deste texto que permita ao analista criar ali um sentido novo, inesperado, produzindo uma outra verdade sobre o texto.

Neste sentido, a análise das entrevistas atuou como uma tentativa de acesso não só ao que o participante havia dito explicitamente, mas também a sentidos não intencionais presentes em seu discurso.

\section{Resultados e discussão}

A presente discussão se baseia predominantemente nos resultados obtidos a partir das segundas entrevistas, nas quais a relação dos adolescentes com personagens literários foi mais explorada. Contudo, os dados das primeiras entrevistas também foram aproveitados, ainda que em menor escala, por servirem de complemento às análises.

Com apontado por Porcacchia, Barone e Costa (2016), o contato com a literatura pode auxiliar o adolescente a falar de si, por oferecer uma possibilidade de narração e ressignificação de suas vivências e experiências.
Entre as obras literárias mais mencionadas durante as entrevistas, destaca-se $A$ seleção, amplamente discutida em uma das segundas entrevistas e citada por seis participantes durante as primeiras entrevistas, todas do gênero feminino. A seleção é uma saga que se passa num país regido por uma monarquia, cujo príncipe organiza uma seleção com diversas garotas de todas as partes do país, para que possa conhecê-las e, eventualmente, eleger uma delas para ser sua esposa. A história se assemelha muito ao conto clássico da Cinderela, no qual é organizado um baile para que o príncipe escolha sua futura rainha. Dowling (1981/1995, apud Cassepp-Borges, 2007) descreveu pela primeira vez o chamado Complexo de Cinderela como um fenômeno no qual mulheres tinham o desejo inconsciente de abdicar da vida profissional para dedicar-se somente ao casamento, submetendo-se aos cuidados paternais do marido. Como levantado por Cassepp-Borges (2007), ao buscar sua identidade, a mulher depara com condições sociais adversas, marcadas pela repressão e a opressão, de forma que o Complexo de Cinderela poderia ser considerado uma defesa a essa pressão social que convoca as mulheres a se lançar no mundo profissional e dar conta da gestão da família ao mesmo tempo. Desta forma, a fantasia de escapar dessa pressão por meio de um casamento que lhe poupasse da carreira profissional apresentar-se-ia como um escape atraente.

Tendo em vista que a questão da proximidade com o vestibular e a cobrança por desempenho do colégio foi retomada em diversas entrevistas, a preferência das entrevistadas por uma obra na qual a personagem principal ascende para uma vida confortável por meio de um casamento pode representar uma identificação inconsciente com essa personagem que se retira da competição do mercado de trabalho para acomodar-se na vida marital. Contudo, vale ressaltar que a predominância de participantes do gênero feminino favoreceu o destaque deste aspecto, sendo possível considerar que, caso contássemos com mais participantes do gênero masculino, outras questões emergiriam.

Costa, Lima e Pinheiro (2010, p. 98) discutem o crescente desinteresse de adolescentes pelos conteúdos apresentados na formação escolar, afirmando que, para os adolescentes, "a formação em si não parecia lhes oferecer nenhuma referência em termos de ideais". Nas entrevistas realizadas, porém, o que encontramos foi justamente o contrário. Os adolescentes pareciam extremamente tensionados com 
o vestibular, preocupando-se com o investimento no conhecimento desde a entrada no ensino médio, sempre visando a recompensa de tal investimento, que seria um bom desempenho nos vestibulares e uma vaga em alguma universidade renomada.

Uma das entrevistadas que considerava America Singer, protagonista da saga $A$ seleção, como sua personagem favorita foi uma estudante que cursava o primeiro ano do ensino médio no momento da entrevista. Essa opção pareceu ocorrer por já enxergar aspectos semelhantes entre suas personalidades, indicando uma identificação com quem já é. Contudo, há também aspectos identificatórios relacionados a um ideal de Eu, uma vez que afirma que há características de America que parece interpretar que deveria ter. Ao final de sua segunda entrevista, ela comentou acerca de sua preocupação com o vestibular, afirmando que deseja cursar Engenharia na Escola Politécnica da Universidade de São Paulo, o que parece apontar para um investimento significativo em relação ao vestibular e, consequentemente, em seus aspectos competitivos. Em sua primeira entrevista, afirma se interessar por obras de ficção, pois "eu gosto de imaginar como as coisas poderiam ser, como elas poderiam ser diferentes do que são". Desta forma, encantar-se com a história de uma jovem que é retirada da competição do mercado de trabalho por meio de um casamento pode representar uma fantasia de escape que dialoga diretamente com as angústias desse momento vivido pela entrevistada, ao mesmo tempo que indica a manutenção de ideais relacionados à formação.

Além da saga $A$ seleção, as outras obras mais citadas tanto nas primeiras quanto nas segundas entrevistas pelos adolescentes foram as sagas Harry Potter e Percy Jackson, que, em muitos aspectos, são narrativas semelhantes. Em ambas as histórias os protagonistas são apresentados, inicialmente, como crianças em desvantagem, que enfrentavam problemas no ambiente familiar e/ou na escola. Contudo, quase ao mesmo tempo em que adentram o período da puberdade, os protagonistas se descobrem parte de um mundo fantástico, nos quais ocupam papéis de extrema importância. Dessa forma, identificar-se com tais personagens pode apontar para uma dimensão de reparação narcísica.

Quanto ao ambiente familiar que habitavam antes de descobrirem tais mundos alternativos e fantásticos, tanto Harry quanto Percy encontravam-se, de alguma forma, em dificuldades. No entanto, com o início das reviravoltas que passam a operar em suas vidas, as questões familiares que os descontentam vão se resolvendo. Freud (1996) deu o nome de "romance familiar" a fantasias de que a família verdadeira não seria a própria, mas, sim, outra, melhor e, geralmente, de posição social mais elevada. Com esta fantasia se conseguiria representar o afastamento da família, movimento que amadurece com a puberdade.

Como apontado por Freud (1996, p. 128), à medida que vai se decepcionando com os pais, o sujeito vai alimentando devaneios "de que é uma criança adotada, ou de que o pai ou a mãe não passam de um padrasto ou de uma madrasta". No caso de Percy Jackson, a identificação com os devaneios característicos do "romance familiar" é ainda mais explícita, uma vez que o jovem descobre ser filho de Poseidon, o deus grego do mar. Na história de Harry, contudo, todos os possíveis aspectos negativos de seus pais, já falecidos no início da história, estão retidos em seus tios. De alguma forma, podemos supor que tal identificação com histórias de reparação narcísica também podem fazer sentido para adolescentes extremamente tensionados com os desafios de assumir a vida adulta, voltando-se para personagens que facilmente ocupam a posição de Ideal de Eu.

Além disso, ambos os protagonistas de tais sagas parecem representar o que Winnicott (1999) descreve como um conflito entre autonomia e dependência, por se mostrarem, ao mesmo tempo, tão desafiadores e, ainda assim, tão dependentes de cuidados. É perceptível que, em diversos momentos das histórias, os jovens heróis desafiam as regras e obtêm sucesso, mas frequentemente necessitam do auxílio de personagens mais sábios e mais velhos, que lhes oferecem algum tipo de ajuda. Os adolescentes entrevistados também manifestaram o desejo de sair de casa e morar sozinhos; contudo, parecem temer o ingresso na faculdade e o início da vida adulta. Assim, é possível que tais sagas dialoguem diretamente com esses adolescentes caracterizados por tal mistura de desafio e insegurança (Winnicott, 1999).

A noção de moratória social, explorada por Calligaris (2000), supõe que púberes já estariam prontos para assumir os papéis reservados a adultos na sociedade, mas são impedidos sob a afirmação de que ainda devem esperar para serem considerados adultos, como se ainda não estivessem prontos. Curiosamente, ocorre justamente o contrário com os personagens mais populares entre os adolescentes 
entrevistados, de forma que, em suas narrativas, eles são lançados a enfrentar grandes obstáculos, independentemente de sua idade. Desta forma, histórias como as de Percy Jackson e Harry Potter, tão queridas por adolescentes, parecem auxiliar a equacionar a insegurança associada à moratória, mostrando-lhes capazes de enfrentar os desafios da vida adulta.

\section{Considerações finais}

Ao analisar os processos de identificação com personagens literários na adolescência, encontram-se três aspectos identificatórios nas relações que os adolescentes estabeleciam com personagens de obras literárias: identificação com quem já se é, no qual os adolescentes ressaltaram suas semelhanças com os personagens citados; identificação com quem gostaria de ser, no qual os personagens citados ocupavam um lugar de Ideal de Eu para os adolescentes; e identificação com quem gostaria de ter como par, no qual os personagens ocupavam um lugar de ideal de objeto. Considerando que todos os entrevistados eram estudantes do ensino médio, a questão da tensão em relação ao vestibular apareceu em diversas entrevistas, relacionando-se também com os personagens citados pelos adolescentes. Personagens como Harry Potter e Percy Jackson foram os que mais frequentemente ocupavam um lugar de Ideal de $\mathrm{Eu}$, inclusive parecendo atuar num sentido de reparação narcísica, pois são personagens que vencem todas as adversidades que lhes são apresentadas. Também se deparou com diversas adolescentes que elegeram como sua favorita uma personagem que ascende na vida por meio de um casamento com um membro da realeza, à semelhança do fenômeno descrito nos anos 1980 como o Complexo de Cinderela. Neste caso, parece que houve um investimento na fantasia de uma narrativa na qual não se precisaria competir no mercado de trabalho para alcançar algum tipo de sucesso, sem prejuízo do esforço consciente e cotidiano no estudo e da disputa pelas vagas universitárias.

As entrevistas também pareceram confirmar a literatura como um recurso transicional, que faz referência à "área intermediária entre o subjetivo e aquilo que é objetivamente percebido" (Winnicott, 1971/1975, p. 15), de forma a oferecer acesso a possibilidades de vida social, amorosa e profissional.

\section{Referências}

André, J. (2001). Feminilidade adolescente. In M. R. Cardoso (Org.). Adolescência: reflexões psicanalíticas (pp. 29-39). Rio de Janeiro: Nau.

Ariès, P. (1981). História social da criança e da família. Rio de Janeiro: LTC.

Bettelheim, B. (2015). A psicanálise dos contos de fadas (30ª ed.). (A. Caetano, trad.). São Paulo: Paz e Terra. (Obra original publicada em 1976).

Calligaris, C. (2000). A adolescência. São Paulo: Publifolha.

Candido, A. (2004). O direito à literatura. In A. Candido. Vários escritos (pp. 169-191). Rio de Janeiro: Duas Cidades/ Ouro sobre Azul.

Cassepp-Borges, V. (2007). Identificação dos adolescentes de hoje com a personagem de cinderela. Boletim de Psicologia, 57(127), 239-254.

Corso, D. L., \& Corso, M. (2006). Fadas no divã: psicanálise nas histórias infantis. Porto Alegre: Artmed.

Costa, R. P. B., Lima, M. C. P., \& Pinheiro, C. V. Q. (2010). Os impasses da educação na adolescência contemporânea. Boletim de Psicologia, 60(132), 97-106.

Figueiredo, L. C., \& Minerbo, M. (2006). Pesquisa em psicanálise: algumas ideias e um exemplo. Jornal de Psicanálise, 39(70), 257-278.

Freud, S. (1996). Romances familiares. In S. Freud. Obras completas de psicanálise: volume IX. Rio de Janeiro: Imago. (Obra original publicada em 1908).

Freud, S. (2010). Obras completas, volume 12: Introdução ao narcisismo: ensaios de metapsicologia e outros textos (1914-1916). (P. C. de Souza, trad.). São Paulo: Companhia das Letras.

Freud, S. (2011a). O eu e o id. In S. Freud. Obras completas, volume 16: O eu e o id, "autobiografia" e outros textos (1923-1925) (pp. 13-74). (P. C. de Souza, trad.). São Paulo: Companhia das Letras. (Obra original publicada em 1923) 
Freud, S. (2011b) Psicologia das massas e análise do eu. In S. Freud. Obras completas, volume 15: Psicologia das massas e análise do eu e outros textos (1920-1923) (pp. 13-113). (P. C. de Souza, trad.). São Paulo: Companhia das Letras. (Obra original publicada em 1921).

Freud, S. (2016). Três ensaios sobre a teoria da sexualidade. In S. Freud. Obras completas, volume 6: Três ensaios sobrea teoria da sexualidade, análise fragmentária de uma histeria ("O caso Dora") e outros textos (1901-1905) (pp. 13-172). (P. C. de Souza, trad.). São Paulo: Companhia das Letras. (Obra original publicada em 1905).

Grunberger, B., \& Chasseguet-Smirgel, J. (1997) L'identification, l'autre, c'estmoi. Collection Les Grandes Découvertes de la Psychanalyse. Paris : Tchou.

Manzini, E. J. (1990/1991). A entrevista na pesquisa social. Didática, 26/27, 149-158.

Manzini, E. J. (2004). Entrevista semiestruturada: análise de objetivos e de roteiros. Seminário internacional sobre pesquisa e estudos qualitativos, (2). Bauru: USC.

Minayo, M. C. S. (1994) Ciência, técnica e arte: o desafio da pesquisa social. In M. C. S. Minayo (Org.). Pesquisa social: teoria, método e criatividade (pp. 9-29). Petrópolis: Vozes.

Pinheiro, T. (2001). Narcisismo, sexualidade e morte. In M. R. Cardoso (Org.). Adolescência: reflexões psicanalíticas (pp. 68-79). Rio de Janeiro: Nau.

Porcacchia, S. S., Barone, L. M. C., \& Costa, B. H. R. (2016). A literatura como intervenção psicopedagógica com adolescente. Revista Psicopedagogia, 33(100), 60-66.

Saraiva, J. A., Kaspari, T., \& Welter, M. R. (2018). Da leitura na escola para a leitura do mundo: roteiros de leitura como proposta pedagógica. Caderno Seminal Digital, 29(29), 32-65.

Saraiva, J. A., Mügge, E., \& Kaspari, T. (2019) Formação do leitor: experiência intelectual e afetiva. Revista do Programa de Pós-Graduação em Letras da Universidade de Passo Fundo, 15(2), 264-282.

Satrapa, A. (2002). A utilização de histórias no manejo terapêutico de pacientes hospitalizados. Journal of Human Growth and Development, 12(2), 58-64.

Silva, E. L., \& Menezes, E. M. (2005). Metodologia da pesquisa e elaboração de dissertação. (4 ed. rev. atual). Florianópolis: UFSC.

Soares, D. H. P., Aguiar, F., \& Guimarães, B. F. (2010). O conceito de identificação no processo de escolha profissional. Aletheia, 32, 134-146.

Winnicott, D. W. (1971/1975). Objetos transicionais e fenômenos transicionais. In D. W. Winnicott. O brincar e a realidade (pp. 13-44). Rio de Janeiro: Imago.

Winnicott, D. W. (1999). A luta para superar depressões. In D. W. Winnicott. Privação e delinquência (3ª ed.) (pp. 163-175) (A. Cabral, trad.). São Paulo: Martins Fontes.

\section{Marina Gonçalves Gonzaga dos Santos}

Graduada em Psicologia pela Universidade Federal de São Paulo e mestranda em Psicologia Clínica pela Universidade de São Paulo, Santos - SP. Brasil.

E-mail: marinagonzagasts@gmail.com

(1) https://orcid.org/0000-0002-4294-067X

\section{Sidnei José Casetto}

Docente da Universidade Federal de São Paulo, Santos - SP. Brasil.

E-mail: sidnei.casetto@unifesp.br

(1) https://orcid.org/0000-0002-7481-5312

A pesquisa recebeu financiamento por meio do Programa Institucional de Iniciação Científica do Conselho Nacional de Desenvolvimento Científico e Tecnológico (CNPq) no ano de 2017. 
Endereço para envio de correspondência:

Universidade Federal de São Paulo, Departamento de Saúde, Clínica e Instituições. Rua Silva Jardim, 136, Vila Mathias. CEP: 11015-020. Santos - SP. Brasil.

Recebido 29/10/2018

Aceito 02/03/2020

Received 10/29/2018

Approved 03/02/2020

Recibido 29/10/2018

Aceptado 02/03/2020

Como citar: Santos, M. G. G., \& Casetto, S. J. (2020). Os Processos de Identificação na Adolescência e sua Relação com Obras Literárias: Relato de Pesquisa. Psicologia: Ciência e Profissão, 40, 1-12.

https://doi.org/10.1590/1982-3703003215913

How to cite: Santos, M. G. G., \& Casetto, S. J. (2020). The Identification Processes in Adolescence and its Relation to Literary Works: Research Report. Psicologia: Ciência e Profissão, 40, 1-12.

https://doi.org/10.1590/1982-3703003215913

Cómo citar: Santos, M. G. G., \& Casetto, S. J. (2020). Los Procesos de Identificación en la Adolescencia y su Relación con obras literarias: Informe de Investigación. Psicologia: Ciência e Profissão, 40, 1-12.

https://doi.org/10.1590/1982-3703003215913 